\title{
Jornada mundial de la paz, 1999 El siglo XX y los derechos humanos
}

Es necesario leer las veinte páginas del breve mensaje de Juan Pablo II, del 1 de enero de 1999, desde la perspectiva histórica que el mismo Papa indica en la introducción: desde su primera encíclica "Redemptor hominis", 1979, que pone de relieve "la importancia de los derechos humanos" (p. 1). A su vez, en la introducción de esta encíclica, Juan Pablo II afirma que él ha recibido una herencia de los anteriores Papas, remitiéndonos a la defensa de los derechos humanos en el Concilio Vaticano II y en Juan XXIII'. Desde esta perspectiva y desde la historia de un siglo que termina, el mensaje del Papa es y puede ser una "piedra de escándalo": son muchos los que se van a tropezar en ella.

Conviene recordar que Juan Pablo II es polaco de nacimiento, un país crucificado entre dos ladrones, Rusia y Alemania. El ha conocido los desmanes y atrocidades cometidos por ambos imperios contra los derechos humanos. El ha sido testigo de la desintegración, sin derramamiento de sangre, de los llamados socialismos reales, o regímenes comunistas del este europeo, tal como lo conmemora en el capítulo tercero de la encíclica Centéssimus annus, 1991. En esta encíclica, luego de la caída del comunismo, el Papa mostraba cierto grado de confianza, en forma de pregunta ( $\left.^{0} 41\right)$ en la economía de empresa o ¿economía de mercado?, como la posible respuesta a la defensa de los derechos humanos. Hoy, al terminar el siglo, habiendo recorrido tantos países del mundo, Juan Pablo II reconoce y afirma que la lógica del mercado tampoco es la solución para este mundo.

Pero, este mensaje del Papa va más allá: recorriendo transversalmente el siglo XX, Juan Pablo II no sólo dice que estos sistemas han fracasado como modelos económicos, sino que, en la defensa e imposición de esas ideologías económicas, estos regímenes han cometido graves crímenes contra la humanidad. El Papa dice algo que habitualmente silencian los textos clásicos de economía de ambos sistemas: éstos nos presentan las bondades de sus objetivos, los éxitos esperados o logrados por el plan o por el mercado, hablan de producto nacional, de su crecimiento, de su rebalse para todos... En ninguno de estos textos clásicos aparece una 
arqueología histórica de los crímenes contra la humanidad que han jalonado su historia. Como que esa no fuera tarea de los economistas y de la economía, que se enuncia como.jna ciencia-social.

Hoy día se está escribiendo e investigando mucho, y con toda razón, sobre el irrespeto a los derechos de la naturaleza del exterminio del medio ambiente. Sin embargo, es tanto y mucho más necesario descubrir y describir la exclusión y el exterminio, cruento o incruento, de una parcela de la humanidad. Es humanamente lógico y razonable que rechacemos aquellos modelos económicos, cuya historia está salpicada de sangre, sobre todo si pretenden ocultar esta negra historia o cuando la justifican como un mal menor. Hay que despuntar la cirugía plástica que utilizan los textos clásicos y sacar a luz sus crímenes contra la humanidad. Esto es lo que hace Juan Pablo II en este breve mensaje sobre la paz, para quien quiere leer y entender sus líneas y sus entrelíneas.

\section{Los claroscuros del siglo $\mathrm{XX}$}

En el mensaje del primero de enero de 1999, Juan Pablo II nos lleva de la mano en un recorrido sobre el siglo XX. Para las personas de edad es una historia vivida; para los más jóvenes es una memoria mejor o peor leída, y para todos es un siglo de contrastes y claroscuros. El siglo XXI comenzará con los mismos desafíos e interrogantes con que termina el presente siglo. Los problemas no cambian por cambiar las hojas del calendario. Por ello conviene dejamos llevar de la mano y reflexionar sobre nuestro siglo. Los juicios de valor y las impresiones pueden ser algo diferentes.

Estamos impresionados por los grandes avances tecnológicos, los malos y los buenos; los que se desarrollaron con las grandes guerras y la carrera armamentística, los que hacen posible destruir el mundo y la humanidad con la energía atómica o los gases letales. También los buenos, los que nos comunican al instante con todos los rincones de un mundo, que hoy llaman "aldea"; o los que pueden mejorar la vida y la biotecnología. Estamos impresionados por el tamaño gigante de empresas que facturan cada año un volumen de ventas veinticinco veces mayor que nuestros productos nacionales; y estamos más impresionados cuando se fusionan dos megaempresas para constituir otra megaempresa con mayúscula. Estamos impresionados cuando nos dicen que el mercado de capitales financieros moviliza diariamente 1,2 trillones de dólares. Como no entendemos esa cifra, nos dicen que en sólo cuatro días de juego en la bolsa de valores se moviliza un flujo de dinero superior al Producto Interno Bruto anual de Estados Unidos, y seguimos sin entender esas cifras...

Estamos impresionados porque la televisión nos ha mostrado, al minuto y al segundo, la operación "Zorro del Desierto", y estamos sobrecogidos porque esas bengalas que brillan en la noche, como un árbol de Navidad, hieren y matan a muchos civiles indefensos. Estamos impresionados porque en un país poderoso 
pueden destituir a un presidente porque manipuló los documentos de un informe público, o porque cometió perjurio para escamotear un desliz amoroso. Estamos impresionados porque los organismos de justicia afirman que pueden enjuiciar y sentenciar a jefes de Estado, que cometieron delitos graves en su país, pese a la llamada inmunidad política.

Estamos impresionados porque, al mismo tiempo que el "mercado" unifica al mundo como un solo globo, los rencores étnicos, la xenofobia y las guerras religiosas lo parcelan en fracciones irreconciliables. Sobre todo nos impresiona que, pese a los grandes avances tecnológicos, económicos y financieros, crezcan a la par el desempleo, la pobreza, la violencia y la insolidaridad. También nos impresiona el irrespeto y el mal trato que, entre todos, hemos inflijido a la naturaleza. El siglo XX ha sido contradictorio: la tecnología, las mercancías y las finanzas crecen al mismo tiempo que se devalúan los derechos humanos. Con toda razón, Juan Pablo II dice que "El secreto de la paz verdadera reside en el respeto de los derechos humanos".

El siglo XX no ha recibido calificaciones muy positivas. En otros comentarios hemos recordado la dura sentencia del gran músico Yehudi Menuhin: "Despertó las mayores esperanzas que concibió la humanidad y destruyó todas las ilusiones e ideales". Más breve y no menos contundente, el juicio de Isaiah Berlín: "El más terrible de la historia de Occidente". Y hay algo más que el holocausto judío. También Lester Thurow habla de "La guerra del siglo XXI" (Head to head). Pero donde hay guerra, violencia y desilusión, también anida la esperanza, la bondad y la utopía del arrepentimiento y de la conversión. Por eso queremos reflexionar sobre estos claroscuros del siglo XX. El mérito del mensaje de Juan Pablo II es que, partiendo de estos claroscuros, desciende a una traducción y aplicación concretas de estos conceptos —algo etéreos y abstractos — de la dignidad de las personas, de los derechos humanos, de los valores morales y del respeto a la naturaleza. Hay personas, hechos y valores que comenzamos a apreciarlos después de que los hemos marginado o irrespetado. Tal el caso de la dignidad de las personas y de los derechos humanos.

\section{Los crímenes contra la humanidad}

El Papa titula esta parte del mensaje: "Respeto de la dignidad humana; patrimonio de la humanidad". Una de las páginas negras del siglo XX han sido los crímenes contra la humanidad. Ninguno de los grandes sistemas y pocos países en el mundo se salvan de esta aberración humana. Juan Pablo II, que además de polaco ha recorrido buena parte del mundo, se expresa con nombres y apellidos. "La historia contemporánea ha puesto de relieve de manera trágica el peligro que comporta el olvido de la verdad sobre la persona humana. Están a la vista los frutos de ideologías como el marxismo, el nazismo y el fascismo, así como los mitos de la superioridad racial, del nacionalismo y del particularismo étnico. No 
menos perniciosos, aunque no siempre tan vistosos, son los efectos del consumismo materialista, en el cual la exaltación del individuo y la satisfación egocéntrica de las aspiraciones personales se convierten en el objetivo último de la vida. En esta perspectiva, las repercuciones negativas sobre los demás son consideradas del todo irrelevantes" (pp. 2-3). El neoliberalismo puede y debe darse por aludido porque el Papa le dedica más líneas y porque lo sentencia con una grave condena: para el neoliberalismo lo que sucede fuera del mercado es "del todo irrelevante". Difícil decir más en menos líneas.

El Papa nos sitúa ante un triste pasado y un triste presente. Los rescoldos neofascistas y nazistas de la superioridad racial cobran de tiempo en tiempo nuevos aires ${ }^{2}$. Los nacionalismos y los particularismos étnicos se traducen en incontables víctimas y en degradados victimarios fundamentalistas. Después del juicio de Nüremberg, condenatorio de los crímenes contra la humanidad perpetrados por el nacional-socialismo, otros historiadores (soviéticos y no soviéticos) abren similar juicio contra el comunismo?. A su vez, el caso Pinochet, símbolo tardío de tantos meritocráticos de igual condena, muestra que desde Occidente (la CIA comprendida) se han cometido similares crímenes contra la humanidad.

Por ello, el Papa hace referencia a "la reciente iniciativa de una conferencia Diplomática de las Naciones Unidas que, con una deliberación específica, ha aprobado los Estatutos de una Corte Penal Internacional, destinada a determinar las culpas y castigar a los responsables de los crímenes de genocidio, crímenes contra la humanidad, crímenes de guerra y de agresión. Esta nueva institución, si se constituye sobre buenas bases jurídicas, podría contribuir progresivamente a asegurar a escala mundial una tutela eficaz de los derechos humanos"(p. 12).

Después de la guerra-fría ha llegado la era de la paz-violenta que Lester Thurow describe como la guerra económica. Bajo la ley del mercado, bajo las armas del intercambio desigual y excluyente, se ocultan silenciosamente millones, como el pobre Lázaro (p. 21), a quienes el modelo considera “del todo irrelevantes”. Baste leer los documentos de antecedentes de la cumbre mundial sobre el desarrollo social, en Copenhague, en 19954. "La rápida carrera hacia la globalización de los sistemas económicos y financieros, a su vez, hace más clara la urgencia de establecer quién debe garantizar el bien común y global, y la realización de los derechos económicos y sociales. El libre mercado, de por sí, no puede hacerlo..." (p. 14). Sobre esta parte del mensaje volveremos más adelante, porque se trata de una novedad de crímenes sin ruido, sin armas y sin campos de concentración.

\section{Clasificación histórica de los crímenes}

Es necesario detenerse en este recuento histórico por varias razones. Juan Pablo II cita expresamente la misma clasificación de crímenes que distingue el juicio de Nüremberg, en 1945, al avalar la constitución de la Corte Penal Internacional (p. 10). Frente a los que se refugian en la inmunidad de jefes de Estado y frente a 
los que quieren limpiar el pasado con la consigna del perdón y olvido, es menester "asegurar a escala mundial una tutela eficaz de los derechos humanos". En segundo lugar porque vuelven a renacer brotes fascistas y neo-nazis en varias esquinas del mundo, que incluso niegan cínicamente la existencia pasada de esos crímenes. En tercer lugar, porque los crímenes juzgados y sentenciados en Nüremberg, se siguen cometiendo bajo nuevas formas y modalidades, en la segunda mitad del presente siglo. Finalmente, porque el relato concreto de estos crímenes ayudará a crear una conciencia más clara de los derechos humanos y a aplicar la justicia allí donde se siguen cometiendo.

Si nos ceñimos al siglo XX no significa ello una indulgencia sobre los siglos pasados. Siempre hubo guerras y crímenes de guerra y sobre todo hubo enormes genocidios. Casi todos los países europeos, de estirpe cristiana, tienen sobre sus conciencias el pecado de la esclavitud y de la trata de negros e indígenas. Estados Unidos, que se presentan como líderes de la democracia mundial, no deben olvidar el apartheid y la esclavitud de los negros, junto con el exterminio casi total de los aborígenes norteamericanos. Parece que nuestro siglo XX ha magnificado esta triste historia, tanto en números cuantitativos como en refinamientos sádicos y nuevas tecnologías de muerte. Los historiadores subrayan la influencia causal que las guerras, mundiales y nacionales, han tenido en la gestación de estos crímenes. La guerra está hecha para matar e irrespetar al enemigo, sea extranjero o conciudadano, y deja huellas indelebles en quienes siguen haciendo los mismos crímenes sin remordimiento de conciencia. Por eso, no se redimen las personas con el perdón y el olvido ni con las inmunidades políticas.

Sin entrar en muchos detalles históricos, baste recordar que "La cuestión de un crimen cometido por un Estado fue abordada por primera vez, desde un ángulo jurídico en 1945, en el tribunal de Nüremberg instituido por los aliados para juzgar los crímenes nazis. La naturaleza de estos crímenes quedó definida en el artículo 6 del estatuto del tribunal, que señala tres crímenes mayores: los crímenes contra la paz, los crímenes de guerra y los crímenes contra la humanidad"s. Aunque no fue el nacional-socialismo el primer Estado autor de similares crímenes, sí fueron ellos los que en forma más notoria se enfrentaron a un tribunal internacional. La clasificación de estos crímenes servirá de pauta para acusar a otros Estados que, antes y después del nazismo, realizaron similares atropellos contra la dignidad humana.

Los crímenes contra la paz aparecen definidos por el artículo $6 a$ y se refieren "a la dirección, la preparación, el desencadenamiento o la realización de una fuerza de agresión, o de una guerra en que se violen tratados, pactos o acuerdos internacionales, o la participación en un plan concertado o en una conspiración para la realización de uno cualquiera de los actos precedentes".

Los crímenes de guerra aparecen definidos en el artículo $6 b$ como "las violaciones de las leyes y costumbres de la guerra. Estas violaciones comprenden, sin limitarse a estas conductas, el asesinato, los malos tratos o la deportación para 
realizar trabajos forzados o con cualquier otra finalidad, de las poblaciones civiles en los territorios ocupados, el asesinato o los malos tratos de los prisioneros de guerra o de ld́s personas localizadas en el mar, la ejecución de rehenes, el saqueo de bienes públicos y privados, la destrucción sin motivo de ciudades y pueblos o la devastación no justificada por las exigencias militares". La convención de la Haya de 1907 estipulaba: "En tiempo de guerra, las poblaciones y los beligerantes permanecen bajo el imperio de los principios de los derechos de gentes tal y como se derivan de los usos establecidos por las naciones civilizadas, por las leyes de la humanidad y por las exigencias de la conciencia pública".

La expresión de crimenes contra la humanidad apareció por primera vez el 18 de mayo de 1915, en una declaración contra Turquía, suscrita por Francia, Inglaterra y Rusia, en relación con la matanza de los armenios calificada de "nuevo crimen de Turquía contra la humanidad y la civilización". Las exacciones nazis impulsaron al tribunal de Nüremberg a definir la noción en el artículo $6 c$ : "El asesinato, el exterminio, la reducción a la esclavitud, la deportación y cualquier otro acto inhumano cometido contra las poblaciones civiles, antes o durante la guerra, o las persecuciones por motivos políticos, raciales o religiosos, cuando estos actos o persecuciones hayan o no constituído una violación del derecho intemo del país en que fueron perpetrados, fueran cometidos a continuación de cualquiera de los crímenes que entran dentro de la competencia del tribunal. o en relación con ese crimen".

Tras el genocidio de los judíos cometido por los nazis, y a fin de precisar el artículo $6 c$, la noción fue definida por una convención de Naciones Unidas el 9 de diciembre de 1948: "Se entiende por genocidio cualquiera de los actos mencionados a continuación, cometidos con la intención de destruir en todo o en parte a un grupo nacional, étnico, racial o religioso, como tal: $(a)$ asesinatos de miembros del grupo; (b) atentado grave contra la integridad física o mental de los miembros del grupo; (c) sumisión intencionada del grupo a condiciones de existencia que deben acarrear su destrucción física total o parcial; (d) medidas que pretenden estorbar los nacimientos en el seno del grupo; (e) traslados forzados de niños del grupo a otro grupo"*.

La constitución de la Corte Penal Internacional, en 1998, y la repercusión internacional que está teniendo el general Pinochet..., actualizan los tres acápites del artículo $6^{\circ}$ de los estatutos de Nüremberg. Los profesionales del derecho internacional de gentes seguirán afinando y aplicando las cláusulas aquí mencionadas. Por nuestra parte, nos dejamos impresionar por los relatos estadísticos de estos crímenes, uniéndonos al grito del "basta ya".

\subsection{Los crímenes del terror nazi}

"Los nazis hicieron del antisemitismo un programa en el contexto de la grave crisis social y económica que vivía Alemania a finales de la década de los veinte, 
y movilizaron su poderosa maquinaria de propaganda con el fin de culpabilizar a los judíos de todos los males, reales o ficticios, que afectaban a los alemanes. Los dirigentes nazis no cesaron de repetir que los eslavos eran una raza inferior y que los judíos no eran seres humanos... Las propuestas antisemitas se plasmaron en las leyes de Nüremberg, septiembre de $1935 \ldots$.., definiendo la ciudadanía en términos raciales al calificar a los judíos como no alemanes, tal como estipulan la ley de ciudadanía (sólo los ciudadanos de "sangre alemana" disponían de todos los derechos políticos) y la ley para la proteción de la sangre y el honor alemán (prohibía el matrimonio y las relaciones sexuales entre judíos y ciudadanos de "sangre alemana").

De forma paulatina, los judíos alemanes fueron expulsados de las tareas administrativas, de las fuerzas armadas y de otras profesiones (prohibición de ejercer la medicina, la enseñanza...) y se les expulsó de numerosos negocios; en muchos casos fueron "desposeídos de sus bienes"... Los historiadores hablan de la "noche de los cuchillos", en 1934, o de "la noche de los cristales rotos", en 1938, en que se generalizan las agresiones contra los judíos. Toda esta serie de atropellos contra judíos, eslavos y gitanos... (deportaciones, trabajos forzados, ejecuciones masivas y campos de exterminio) se incrementan, en forma sádicamente programada, una vez iniciada la guerra'. Un relato de los dirigentes nazis o pronazis condenados en el juicio de Nüremberg, dentro y fuera de Alemania, puede leerse en la obra y páginas citadas.

"Hasta la guerra, el terror nazi apuntó hacia algunos grupos. Los opositores al régimen -principalmente comunistas, socialistas, anarquistas, algunos sindicalistas - fueron reprimidos de manera abierta, encarcelados en prisiones y sobre todo internados en campos de concentración, sometidos a severas vejaciones. En total, de 1933 a 1939, alrededor de 20,000 militantes de izquierda fueron ejecutados después de ser juzgados o sin ser juzgados en los campos de concentración y las prisiones. Esto sin mencionar los ajustes de cuentas internas del nazismo, como la noche de los «cuchillos largos» en junio de 1934. Otra categoría de víctimas destinada a la muerte fueron los alemanes de los que se consideraba que no correspondían a los criterios raciales del "gran ario rubio»: enfermos mentales, minusválidos, ancianos. Hitler decidió pasar a la acción aprovechando la guerra: 70,000 alemanes fueron víctimas de un programa de eutanasia mediante el gaseamiento, entre el final de 1939 y el inicio de 1941, hasta que las Iglesias elevaron sus protestas y el programa fue detenido. Los métodos de gaseamiento, puestos entonces a punto, fueron aplicados al tercer grupo, los judíos.

Hasta que se produjo el estallido de la guerra, las medidas de exclusión relacionadas con ellos estuvieron generalizadas, pero su persecución llegó a su apogeo durante la "noche de los cristales rotos", con varios centenares de muertos y 35,000 detenciones en campos de concentración. Hasta que comenzó la guerra, y sobre todo a partir del ataque contra la URSS, no se produjo un desencadenamien- 
to del terror nazi, cuyo balance resumido es el siguiente: 15 millones de civiles muertos en los países ocupados; 5,1 millones de judíos; 3,3 millones de prisioneros de guerra soviéticos; 1,1 millón de deportados muertos en los campos; varios centenares de miles de gitanos. A estas víctimas se añadieron 8 millones de personas condenadas a trabajos forzados y 1,6 millones de detenidos en campos de concentración que no fallecieron". Esto hace un total de 25 millones de víctimas del nazismo.

"El terror nazi ha sobrecogido las mentes por tres razones. En primer lugar porque afectó directamente a los europeos. Además, al haber sido vencidos los nazis y juzgados sus principales dirigentes en Nüremberg, sus crímenes fueron señalados y estigmatizados de manera oficial como tales. Finalmente, el descubrimiento del genocidio perpetrado contra los judíos constituyó un trauma para las conciencias por su carácter en apariencia irracional, su dimensión racista y la radicalidad del crimen"'.

\subsection{El libro negro del comunismo}

Hoy día ya no se puede seguir silenciando y menos ocultando los graves crímenes contra la humanidad cometidos bajo el régimen soviético, inicialmente, y repetidos con similares grados de crueldad por otros países integrados al bloque comunista. Durante un tiempo, los crímenes del nacional-socialismo acapararon la atención mundial y por su parte las cúpulas de los países comunistas trataron de interponer un muro del silencio para que tales crímenes no traspáaran las fronteras nacionales, justificándolos internamente en nombre de la revolución proletaria. Una interrogante inicial que se hacen los historiadores es cómo y por qué un régimen que se define el defensor de la democracia y de la causa trabajadora pudo derivar hacia los mayores crímenes contra la democracia (países democráticos) y contra sus propios conciudadanos.

El historiador Yuri Afasaniev, director del Instituto de Archivos Históricos de Moscú, nos dice que para entender la historia del imperio soviético hay que remontarse a la larga historia del imperio ruso, marcada por una constante conquista y colonización de nuevos territorios, porque durante siglos nunca ha sido estable el trazado de las fronteras occidentales, orientales y meridionales del Estado ruso". El imperio soviético hereda una historia secular de guerras prolongadas y esto va a marcar las conductas y las conciencias del pueblo ruso. Son varios los testimonios que avalarian esta tesis.

Karl Kaustky, principal líder y teórico del socialismo alemán, se refería a este tema en 1920: "Hay que atribuir a la guerra la causa principal de esta transformación de las tendencias humanitarias en una tendencia a la brutalidad... Durante cuatro años, la guerra mundial absorbió la práctica totalidad de la población sana masculina y las tendencias brutales del militarismo alcanzaron el colmo de la insensibilidad y de la bestialidad. Tampoco el proletariado pudo escapar desde 
entonces a su influencia: quedó contaminado por ella en el más alto grado y salió embrutecido bajo todos los puntos de vista. Los que regresaban se sentían demasiado inclinados por las costumbres de la guerra a defender en tiempo de paz sus reivindicaciones e intereses con métodos sangrientos y violencia contra sus conciudadanos. Esto proporcionó uno de sus elementos a la guerra civil"'".

En la cronología de las revoluciones contra el imperio zarista, resalta la figura de Sergei Nechaiev, que Dostoyeusky lo convierte en el personaje revolucionario de su novela Los demonios. En 1869, Nechaiev redactó un Catecismo del Revolucionario, en el que se definía como sigue: "El revolucionario es un hombre perdido de antemano. No posee intereses particulares, asuntos privados, sentimientos, ataduras personales, propiedades, no tiene siquiera nombre. Todo en él queda absorbido por un único interés que excluye todos los demás, por un sólo pensamiento, una pasión: la Revolución. En el fondo de su ser, no sólo en palabras sino también en actos, ha roto cualquier vínculo con el orden público y con todo el mundo civilizado, con todas las leyes, conveniencias, convenciones sociales y reglas morales de este mundo. El revolucionario es un enemigo implacable de todo esto y sólo continúa viviendo para destruirlo más seguramente...".

"Nechaiev tuvo sus émulos. El 1 de marzo de 1887 hubo un atentado contra el zar Alejandro III, que no alcanzó su objetivo. Sus autores, sin embargo, fueron detenidos; entre ellos se encontraba Alekxandr Illich Ulianov, hermano mayor de Lenín, que fue ahorcado junto con cuatro de sus cómplices. El odio de Lenín a este régimen tenía hondas raíces y fue Lenín personalmente quien, a espaldas de los miembros del Buró político, decidió y organizó la matanza de la familia imperial de los Romanov en 1918".

Son múltiples los textos de autores contemporáneos que nos revelan el ambiente de crueldad en que se inicia la Revolución de octubre de 1917 y la guerra civil soviética. Karl Kaustky, en su libro La dictadura del proletariado, en 1918, ya preanunciaba las consecuencias antidemocráticas de un régimen asentado en la dictadura de un único poder y partido, "La oposición entre las dos corrientes socialistas... reposa en la oposición de dos métodos fundamentalmente distintos: el método democrático y el método dictatorial. Ambas corrientes quieren lo mismo, la emancipación del proletariado y con él el de la humanidad a través del socialismo. Pero la vía que unos escogen, los otros la consideran falsa y afirman que sólo puede llevar a la ruina. Reivindicar la libre discusión nos sitúa de entrada en el terreno de la democracia. El objetivo de la dictadura no es refutar la opinión contraria, sino suprimir violentamente su expresión. De este modo, los métodos de la democracia y de la dictadura se oponen de manera irreductible, antes incluso del inicio de la discusión. Una exige la discusión y la otra la niega" (pp. 173).

Haciendo de la democracia el eje de su razonamiento, Kaustky plantea sus interrogantes: "La dictadura de una minoría siempre encuentra su más sólido apoyo en un ejército adicto. Pero cuanto más coloca la fuerza de las armas en el lugar 
de la mayoría, más fuerza a la oposición a buscar su salvación en las bayonetas y en la fuerza de los puños en lugar de recurrir al voto que se le niega. Entonces, la guerra civil se'convierte en el medio de resolver los antagonismos políticos y sociales. Siempre y cuando no reine la más perfecta apatía política y social o el más perfecto desánimo, la dictadura de una minoría estará constantemente amenazada por golpes de Estado o por una guerrilla permanente... A partir de entonces ya no se conseguirá salir de la guerra civil y se verá confrontada en todo momento al peligro de ser aplastada por la guerra civil. Pero no existe mayor obstáculo para la construcción de una sociedad socialista que una guerra intestina... En una guerra civil, cada bando lucha por su existencia y al que pierde le amenaza su más completa aniquilación. La conciencia de esta emenaza es lo que hace tan crueles las guerras"... (pp. 217-219)".

La respuesta que diera Lenín en su opúsculo La revolución proletaria y el renegado Kaustky, testimonia claramente cuál era el pensamiento y la acción del fundador del partido: "El Estado es en las manos de la clase dominante una máquina destinada a aplastar la resistencia de sus adversarios de clase. Desde este punto de vista, la dictadura del proletariado no se distingue nada, en cuanto al fondo, de la dictadura de cualquier otro tipo, ya que el Estado proletario es una máquina destinada a aplastar a la burguesía. La dictadura es un poder que se apoya directamente en la violencia y no está atada por ninguna ley. La dictadura revolucionaria del proletariado es un poder conquistado y mantenido mediante la violencia que el proletariado ejerce sobre la burguesía, un poder que no está atado por ninguna ley"'2. Se trata de una aplicación literal del Catecismo de Sergei Ne-chaiev.

Hay algo que llama la atención en el proceso de autocrítica que hacen oficialmente los actuales supervivientes de los socialismos reales; en la Mesa Redonda de historiadores soviéticos, en 1988, y en el foro de Moscú, en 1989, las críticas y la historiografía se concentran en las purgas, crímenes y poder despótico de Stalin, pero guardan un respetuoso silencio sobre el fundador de esta ideología. También M. Gorbachov, en su Perestroika, siempre se refiere en forma laudable a Lenín. Hubo que esperar los foros de Barcelona, en 1988, y el de La Sorbona, París, en 1990, para que la riada crítica subiera hasta la imagen del fundador del partido, que en 1919 había calificado de "social-traidores" al resto de vías socialistas. Al igual que K. Kaustky, Rosa Luxemburg ya había preanunciado las consecuencias antidemocráticas del régimen instaurado por Lenín.

Otros autores contemporáneos expresan su censura a los métodos aplicados desde el inicio de la revolución bolchevique. Baste citar el lamentable ejemplo de Máximo Gorky, quien en 1922 censura la crueldad del régimen y diez años más tarde justifica la creación de un Instituto de Medicina Experimental en la URSS, en 1933, que utiliza personas (los opositores al régimen) como cobayas de ensayo para los experimentos médicos. Recogemos aquí el texto escrito en 1922 por Máximo Gorky. 
"La crueldad es algo que toda mi vida me ha dejado estupefacto y me ha atormentado. ¿En qué, dónde están las raíces de la crueldad humana? He reflexionado mucho sobre ello y no he comprendido nada y sigo sin comprender nada... Ahora, después de la espantosa demencia de la guerra europea y de los sangrientos acontecimientos de la Revolución... debo señalar que la crueldad rusa no parece haber evolucionado. Se diría que sus formas no cambian... Creo que es una característica propia del pueblo ruso - tan exclusivamente suya como el sentido del humor en los ingleses - una crueldad especial, una crueldad de sangre fría, como si deseara probar los límites de la resistencia humana al sufrimiento, como si quisiera estudiar la persistencia, la estabilidad de la vida. Se percibe en la crueldad rusa un refinamiento diabólico. Hay en ella algo sutil y rebuscado. No podría explicar esta particularidad con las palabras "psicosis" o "sadismo", palabras que en el fondo no explican nada. Si estos actos de crueldad sólo fuesen la expresión de la psicología pervertida de los individuos, podríamos no hablar de ello pues entraría dentro del terreno de la psiquíatra y no del moralista. Pero aquí sólo considero la diversión colectiva a través del sufrimiento... ¿Quiénes son más crueles, los blancos o los rojos? Probablemente lo son por igual, pues unos y otros son rusos. Por lo demás, a la cuestión del grado de crueldad la historia responde muy claramente: el más activo es el más cruel".

Por desgracia, Gorky se convierte de un crítico en un defensor de la revolución proletaria y de los métodos propios de una guerra de exterminio de la clase opositora; con ello demuestra su propia tesis: Máximo Gorky también es ruso. Es la representación de tantos y tantos que, por convencimiento o por instinto de supervivencia, se adherirán a las filas del partido. Dejando de lado otra serie de testimonios y documentos, que pueden consultarse en la bibliografía citada, era menester decir algo sobre el escenario donde se libra la revolución y la guerra civil soviética y la conflictiva herencia recibida del imperio ruso zarista. Datos que podrán explicar, pero nunca justificar los crímenes cometidos por este régimen desde su instauración y llevados a límites sobre todo límite por Stalin y los líderes de otros países comunistas. Una historia que por mucho tiempo se quiso ocultar y negar.

Antes de trasladar un breve relato estadístico de los crímenes contra la humanidad, nacidos del terror y la represión comunista, conviene decir que todos estos relatos están históricamente confirmados por un conjunto de publicaciones oficiales, públicas y privadas, poniendo en primer lugar el "Informe secreto de" Krutchov al pleno del XX Congreso del PCUS, en 1956. En ese mismo año se realiza la invasión de Hungría, revelión sofocada en sangre, seguida de la invasión de Checoslovaquia, en 1968, tronchando la "Primavera de Praga": invasión unánimamente criticada por los partidos socialistas y comunistas de Europa occidental. Se agregarían el “Archipiélago de Gulag” de A. Soljenitsin, la "Mesa redonda" de historiadores soviéticos, editada por la Academia de Ciencias de la URSS, en 1988, el foro 
de Moscú, en 1989, así como las obras de los historiadores Yuri Afasaniev, Mi Rusia Fatal, en 1994, y de Roy Medvedev: Let history judge: the origins and consequences of stalinism, en 1989. Hace años leíamos la obra de V. Krauchenko: “Yo escogí la libertad", en 1949. Una de las obras, aquí citada, El libro negro del comunismo: crímenes, terror y represión, es un ejemplo de esta arqueología histórica. En su edición francesa se vendieron 180,000 ejemplares.

Con este respaldo bibliográfico presentamos algunas referencias estadísticas, a modo de aproximación mínima", que necesitarían largas precisiones pero que, según estimaciones personales, proporciona un aspecto de considerable magnitud y permite señalar de manera directa la gravedad del tema:

- URSS, 20 millones de muertos.

- China, 65 millones de muertos.

- Vietnam, 1 millón de muertos.

- Corea del Norte, 2 millones de muertos.

- Camboya, 2 millones de muertos.

- Europa oriental, 1 millón de muertos.

- América Latina, 150,000 muertos.

- África, 1,7 millones de muertos.

- Afganistán, 1,5 millones de muertos.

- El total se acerca a cien millones de muertos.

Este grado de magnitud oculta grandes diferencias entre las distintas situaciones. Resulta indiscutible que en términos relativos la "palma" se la lleva Camboya, donde Pol Pot, en tres años y medio, llegó a matar de la manera más atroz - hambre generalizada, tortura - aproximadamente a la cuarta parte de la población total del país. Sin embargo, la experiencia maoista sobrecoge por la magnitud de las masas afectadas. En cuanto a Rusia leninista y estalinista, hiela la sangre por su aspecto experimental pero perfectamente reflexionado, lógico y político"13...

Comenzando por la URSS, “puede realizarse un primer balance global de estos crímenes:

- fusilamiento de decenas de miles de rehenes o de personas confinadas en prisión sin juicio y asesinato de centenares de miles de obreros y de campesinos rebeldes entre 1918 y 1922.

- Hambruna de 1922, que provocó la muerte de cinco millones de personas.

- Liquidación y deportación de los cosacos del Don en 1920.

- Asesinato de miles de personas en los campos de concentración, entre 1918 y 1930.

- Liquidación de cerca de 690,000 personas durante la gran purga de 1937-1938.

- Deportación de dos millones de kulaks (agricultores con tierras) o de gente a la que se le calificó de tales, en 1930-1932. 
- Destrucción por el hambre provocado y no auxiliado de seis millones de ucranianos, en 1932-1933.

- Deportación de centenares de miles de personas procedentes de Polonia, Ucrania, los países bálticos, Moldavia y Besarabia, en 1939-1941, y después en 1944-1945.

- Deportación de los alemanes del Volga, en 1941.

- Deportación-abandono de los tártaros de Crimea, en 1943.

- Deportación-abandono de los chechenos, en 1944.

- Deportación-abandono de los ingushes, en 1944.

- La liquidación de la casi totalidad de los oficiales polacos, hechos prisioneros en 1939, de los que sólo son un episodio los 45,000 muertos en las fosas de Katyn.

- Deportación-liquidación de las poblaciones urbanas de Camboya, entre 19751978.

- Lenta destrucción de los tibetanos por los chinos desde $1950 \ldots$

No acabaríamos de enumerar los crímenes del leninismo y del estalinismo, a menudo reproducidos en forma casi idéntica por los regímenes del Mao Zedong, de Kim II Sung, de Pol Pot"14...

Para quien estos datos parescan especulaciones redondeadas, puede consultar provechosamente el Archipiélago de Gulag o la obra más extensa de Roy Medvedev, donde encontrará, en orden cronológico y con miles de nombres y apellidos las víctimas de las purgas sucesivas, a todos los grupos de la población, incluída la liquidación de los grandes "verdugos" o mano visible de Stalin. Es históricamente incomprensible que los textos de exportación del este europeo, entre otros el $\mathrm{Ma}$ nual de Economía Política, ocultaran tales hechos y vertieran cínicamente los mayores calificativos laudatorios del régimen. Esto es tanto más llamativo porque, para esas fechas, ya se tenía amplio conocimiento en toda Europa del "informe secreto" de Krutchov. El ocultamiento planificado de la verdad es un pecado grave que desprestigia radicalmente a ese modelo.

El informe secreto de Krutchov. "El primer gran cambio en el reconocimiento oficial de los crímenes comunistas se sitúa el 24 de febrero de 1956. Esa tarde, Nikita Krutchov, primer secretario, sube a la tribuna del XX Congreso del Partido Comunista de la Unión Soviética, el PCUS. La sesión es a puerta cerrada. Sólo los delegados al Congreso asisten a la misma. En medio de un silencio absoluto, aterrados, escuchan al Primer Secretario del Partido destruir metódicamente la imagen del "padrecito de los pueblos", del "genial Estalin", que fue durante treinta años el héroe del comunismo mundial. Este informe, conocido desde entonces como "el informe secreto", constituye unas de las inflexiones fundamentales del comunismo contemporáneo. Por primera vez, un dirigente comunista del más alto rango reconoció oficialmente, aun- 
que sólo para información de los comunisias, que el régimen que se había apoderado del poder en 1917 había conocido una "derivación" criminal".

Las razones que impulsaron al señor " $K$ " a quebrantar uno de los mayores tabúes del régimen soviético eran múltiples. Su objetivo principal era imputar los crímenes del comunismo sólo a Stalin y así circunscribir el mal y sajarlo a fin de salvar al régimen. Influía igualmente en su decisión la voluntad de desencadenar un ataque contra el clan de los estalinistas, que se oponían con su poder en nombre de los métodos de su antiguo patrón y, por tanto, en el verano de 1957, estos hombres fueron apartados de todas sus funciones. Sin embargo, por primera vez, desde 1934, su "muerte política" no se vio seguida de una muerte real, y se comprende por este simple detalle que los motivos de Krutchov eran más profundos. El, que había sido el jefe máximo de Ucrania durante años y, por esta razón, había llevado a cabo y ocultado gigantescas matanzas, parecía cansado de toda esa sangre. En sus memorias, donde sin duda se concede el papel del bueno de la historia, Krutchov recuerda sus estados de ánimo: "el Congreso va a terminarse; serán adoptadas algunas resoluciones, todas formales. ¿Y qué? Aquellos que fueron fusilados por centenares de miles permanecerán sobre nuestras conciencias".

“De repente apostrofa con durcza a sus camaradas: ¿Qué vamos a hacer con aquellos que fueron detenidos, liquidados?... Ahora sabemos que las víctimas de las represiones eran inocentes. Tenemos la prueba irrefutable de que, lejos de ser enemigos del pueblo, eran hombres y mujeres honrados, dedicados al Partido, a la Revolución, a la causa leninista de la edificación del socialismo y del comunismo... Es imposible ocultar todo. Antes o después, aquellos que están en prisión, en los campos de concentración, saldrán y volverán a sus casas. Relatarán entonces a sus padres, a sus amigos, a sus camaradas lo que sucedió... Por eso estamos obligados a confesar a los delegados todo sobre la manera en que se ha dirigido el Partido durante estos años... ¿Cómo pretender que no sabíamos lo que sucedió?... Sabemos lo que era el reinado de la represión y de la arbitrariedad en el Partido y debemos decir al Congreso lo que sabemos... En la vida de cualquiera que ha cometido un crimen llega un momento en que la confesión le asegura la indulgencia si es que no la absolución"15.

Este informe secreto sigue teniendo una primordial importancia porque la autocrítica nacía desde la misma cúpula del Kremlin, y ya no se podía seguir diciendo que eran las críticas de un disidente; no se podían rechazar, como lo intentaron hacer algunos diarios del partido comunista francés con la obra de V. Krauchenco, en 1949. Sin embargo, los textos clásicos de exportación seguían manteniendo un inútil silencio, cuando en Europa occidental era ampliamente conocido el informe de Krutchov y ya no se podían ocultar por más tiempo los atropellos del régimen, a que hace referencia el mensaje de Juan Pablo II.

Dentro de la historiografía crítica del régimen, otro hito mayor será la Perestroika, del equipo Gorbachov, la Mesa Redonda de historiadores soviéticos y el foro de Moscú... Nombrar estos y otros documentos no obedece a un prurito 
bibliográfico ni menos a un deseo de hacer leña del árbol caído. En los socialismos reales del este europeo, admitido todo el serial de crimenes contra la humanidad, hay una sincera autocrítica, hay -de parte de muchos de sus autores- un arrepentimiento, una petición de perdón y no de olvido. Como decía N. Krutchov, una confesión seguida de un arrepentimiento y quizás de una absolución.

Este proceso de autocrítica no lo escuchamos, de momento, en los teóricos, líderes y patrocinadores del capitalismo neoliberal, incluidas las instituciones financieras internacionales. Tal vez comienzan a vislumbrarse algunas confesiones de los errores cometidos de parte de uno de los presidentes del grupo del Banco Mundial, como puede inferirse del discurso de James D. Wolfensohn: "La otra crisis" (ECA, 1998, pp. 1003-1009).

Hay otra importante razón para explicar la extensión dada a estos relatos de los crímenes contra la humanidad cometidos por los regímenes comunistas. Desde el occidente capitalista se erigió la tesis de que la raíz causal de la descomposición de esos regímenes era el sistema de planificación económica, para deducir de ahí que la solución de la historia estaba en el libre juego del mercado. Pero la raíz última del mal no estaba en la planificación - por cierto totalmente militarizada, verticalista, impositiva y económicamente perniciosa-, sino en la centralización todopoderosa de la convivencia política y social. La planificación económica era un signo externo de la mayor concentración de poder en manos de una minoría siempre privilegiada que, por encima de toda ley y norma ética, llegó a cometer los grandes crímenes contra la humanidad, aquí esbozados. Resulta que en el interior del capitalismo neoliberal nos volvemos a encontrar con similares crímenes contra la humanidad, bajo la cobertura o el escudo del libre mercado.

\section{El libro blanco del capitalismo}

El color de la carátula no blanquea el contenido oscuro de la historia del capitalismo. Juan Pablo II lo dice suficientemente claro. "No menos pemiciosos, aunque no siempre tan vistosos, son los efectos del consumismo materialista, en el cual la exaltación del individuo y la satisfacción egocéntrica de las aspiraciones personales se convierten en el objetivo último de la vida. En esta perspectiva, las repercusiones negativas sobre los demás son consideradas del todo irrelevantes. Es preciso confirmar, sin embargo, que ninguna ofensa a la dignidad humana puede ser ignorada, cualquiera que sea su origen, su modalidad o el lugar en que sucede" (p. 5). Tres páginas adelante, en el acápite dedicado a "El derecho a la vida", el Papa agrega: "Optar por la vida comporta el rechazo a toda forma de violencia. La violencia de la pobreza y del hambre, que aflije a tantos seres humanos; la de la difusión criminal de las drogas y el tráfico de armas; la de los daños insensatos al ambiente natural" (p. 8).

En estos breves textos, Juan Pablo II describe un conjunto de escenarios donde se siguen realizando graves crímenes contra la humanidad. En varios rincones del mundo prosiguen las guerras y las masacres de pueblos enteros, así como prosigue 
el tráfico de armas del norte al sur (pp. 17-18). El Papa integra dos nuevas modalidades de crímenes contra la humanidad, el tráfico criminal de las drogas y el irrespeto al matio ambiente (p. 16). Dirigiéndose más directamente al neoliberalismo, a quien describe por sus objetivos y efectos, le acusa, en primer lugar, por su insensibilidad ante la violencia de la pobreza y del hambre: "las repercusiones negativas sobre los demás son consideradas del todo irrelevantes".

Implícitamente, el Papa acusa al neoliberalismo de no mostrar preocupación y no dar respuesta a un derecho fundamental del hombre: el derecho al trabajo y el derecho a la propia realización (pp. 12-13). En anteriores artículos, sumándonos a lo escrito por tantos autores, hemos tratado de mostrar que el modelo neoliberal ha gestado una economía de exclusión, caracterizada por el creciente desempleo y la mayor desigualdad't . A estos efectos presentes se agrega otra historia de crímenes contra la humanidad en la defensa e imposición forzada de su ideología capitalista.

Tal vez no sea necesario abrumar con citas y estadísticas esta parte del comentario porque los crímenes contra la paz, los crímenes de guerra y los crímenes contra la humanidad son experiencias vividas por y en todos los países desde el cono-sur de Chile y Argentina hasta el trapezio-norte de México, con el beneplácito de la CIA y de algunos gobiemos de Estados Unidos, que financiaron la persecución de opositores y sospechosos, múltiples guerras civiles y que adiestraron a miembros de las fuerzas armadas para cometer los más repugnantes crímenes contra sus conciudadanos. Aquí, el sanbebito era ser filomanxista, filocomunista, filoprogresista o filocontrario... Lo sucedido en nuestra universidad, la UCA, es uno entre miles y miles de ejemplos ${ }^{17}$.

Una ilustrativa coincidencia es que al redactar estas páginas se esté ventilando en Inglaterra el juicio y posible extradicción de Pinochet. Salga lo que salga de este juicio, ha quedado algo muy claro y reclamado por varias naciones: también en Chile se cometieron graves crímenes contra la humanidad, y de carambola la piedra le llega a la CIA y a alguno de los gobiemos de Estados Unidos. Es una seria advertencia para que otros actores de similares crímenes no se aventuren a hacer turismo fuera de su país. Esto encaja en la frase del Papa, avalando la Corte Penal Internacional: "Esta nueva institución, si se constituye sobre buenas bases jurídicas, podría contribuir progresivamente a asegurar a escala mundial una tutela eficaz de los derechos humanos" (p. 12).

Es claro, por repetidas experiencias, que en nuestro continente latinoamericano se han cometido, bajo propias modalidades, graves crímenes contra la humanidad y con ello se han irrespetado los derechos y los valores humanos. Sin embargo, hay una diferencia: en nuestro hemisferio no ha surgido un Krutchov o un Gorbachov que confiese abiertamente que nuestros Estados han cometido esos crímenes contra la humanidad. No se lo hemos oído a Pinochet ni a Bush ni a Reagan, ni a ninguno de similares meritocráticos. Estas confesiones han salido de muchos mártires, que por ello fueron mártires. 
No ha habido confesión porque ha habido ocultamiento de lo realizado. Y había que preguntarse por qué ha habido ocultamiento. Porque si la razón del ocultamiento es la persuasión de que lo hecho está bien hecho, y que se volvería a hacer lo mismo en nombre de la Seguridad Nacional o de otro "dios menor", los propios intereses, entonces no tenemos otra salida que seguir haciendo lo mismo sin remordimiento de conciencia. Entonces estamos peor que en los socialismos reales: no hay confesión ni propósito de enmienda. Una aplicación concreta es la receptividad al informe de la Comisión de la Verdad.

Conocemos la génesis de este documento, a propuesta de las partes dialogantes sobre los acuerdos de paz. El título del informe es: "De la locura a la esperanza". En su parte introductoria hay un acápite esclarecedor: "Fenomenología de la violencia"; merece la pena releerlo porque es un juicio de valor jurídico.

"Un aserto universalmente mantenido establece que el sujeto de toda situación delincuencial es el ser humano, único capaz de voliciones y por tanto de decisiones de voluntad: delinquen los individuos y no las instituciones creadas por ellos. En consecuencia, es a aquellos y no a éstas, a quienes han de aplicarse las penas respectivas establecidas en las leyes. Sin embargo, en ciertos contextos se presentan hechos repetitivos en el tiempo y en el espacio, que parecerían rectificar la premisa anterior. Pueden darse, en efecto, reiteraciones delicuenciales en las que actúen como protagonistas dentro de la misma institución, con analogía inequívoca, individualidades diferentes, más allá del signo político de los gobiemos y de quienes toman las decisiones; lo cual da campo para pensar que las instituciones sí delinquen, dados los mismos comportamientos a manera de constante. Con mayor razón, si a la claridad de las imputaciones se sigue el encubrimiento por parte de la institución a la cual pertenecen los protagonistas implicados y el entorpecimiento institucional frente a las responsabilidades que se desprenden de las investigaciones. En tales circunstancias, es fácil sucumbir a la fuerza de las reiteraciones, para señalar la culpabilidad institucional" (ECA, 1993, p. 164).

Quien haya leído este informe conocerá la serie de túmulos y de puertas cerradas que encontraron los miembros de la Comisión de la Verdad en tantas instituciones públicas. La conclusión era clara: las instituciones públicas habían delinquido (fuerza ammada, administración de la justicia...) y era menester depurarlas y cambiarlas. Pero las instituciones se autodefendían calificando al informe de estupidez e intromisión extranjera. En este campo, la embajada de Estados Unidos se ha destacado por sus altos muros y por sus documentos desclasificados "en negro"; cómplice en el financiamiento y por ello cómplice en el ocultamiento. El informe de la Comisión de la Verdad quedó oculto bajo un montón de "arena", con la precipitada aprobación de la ley de amnistía. Con la consigna de perdón y olvido nos queda sólo la mitad del título del informe: la locura sin esperanza: la misma violencia sigue campeando. No hubo confesión, no ha habido arrepentimiento y sólo nos quedan presupuestos crecientes en seguridad intema y más 
códigos penales. Otro aspecto contradictorio es que los mismos que se negaron a que se descubriera la verdad y se aplicara la debida justicia a los principales actores de estos grandes crímenes, son los que posteriormente más han proclamado y solicitadó la pena de muerte para los autores de nuevos crímenes. Sin duda se sentirán un tanto contrariados porque Juan Pablo II ha pedido a los Estados, en su mensaje de Navidad, la abolición de la pena de muerte.

\section{El libro blanco del neoliberalismo}

Algunos podrán decir que ese historial de crímenes contra la humanidad han sido un repugnante tumor de las décadas de la guerra fría, cuando las ideologías enfrentadas se imponían hacia fuera con la desgastante carrera armamentística y se defendía, desde dentro, con excesivos controles y políticas de terror y represión. Incluso se podrá decir que los teóricos de los modelos económicos no son los teóricos del terror y de las desapariciones masivas. Sin discutir esta posición, que no aceptamos tan simplemente, hay que llevar la reflexión más adelante. Los teóricos de los modelos económicos, ¿hacen teoría de los derechos y valores humanos? O como dice el Papa, en la teorización de los modelos económicos ¿entra como variable clave la dignidad de la persona humana? En los principios filosóficos del modelo, ¿se toman en cuenta, junto con los derechos civiles y políticos, los derechos económicos, sociales y culturales? (p. 6).

En el mensaje de Juan Pablo II hay una frase clave para leer al neoliberalismo: "En esta perspectiva, las repercusiones negativas sobre los demás son consideradas del todo irrelevantes" (p. 5). Este es un rasgo típico, aunque no exclusivo, del neoliberalismo, que el Papa enuncia en el acápite segundo y lo desarrolló en el numeral noveno, bajo el título: "Progreso global en solidaridad". Juan Pablo II toca el tema de la globalización, del mercado y de la permanente crisis financiera mundial. En su brevedad, este mensaje añade nuevos tópicos y avalaría la cátedra universitaria que en la UCA dedicamos al mismo tema (ECA, 600, octubre, 1998). He aquí parte del texto:

"La rápida carrera hacia la globalización de los sistemas económicos y financieros, a su vez, hace más clara la urgencia de establecer quién debe garantizar el bien común y global, y la realización de los derechos económicos y sociales. El libre mercado de por sí no puede hacerlo, ya que, en realidad, existen muchas necesidades humanas que no tienen salida en el mercado. Por encima de la lógica de los intercambios a base de los parámetros y de sus formas justas, existe algo que es debido al hombre porque es hombre, en virtud de su eminente dignidad" (p. 14). Si unimos este párrafo a las palabras antes citadas: "En esta perspectiva, las repercusiones negativas sobre los demás son consideradas del todo irrelevantes", deducimos un radical rechazo del neoliberalismo por cuanto deja de lado los valores y los derechos humanos. Es una actualización de la parábola del Buen Samaritano, que Jesús de Nazaret la dijo, para nosotros, hace casi dos mil años. 
Adicionalmente, y aunque sea en forma de cuña, estas palabras de Juan Pablo Il me recuerdan unas afirmaciones similares de un conocido beneficiario del mercado financiero internacional, George Soros: "Podemos tener una economía de mercado, pero no podemos tener una sociedad de mercado. Además de los mercados la sociedad necesita tener instituciones que sirvan para fines sociales, como la libertad política y la justicia social. Estas instituciones existen en países concretos, pero no en la sociedad global. El desarrollo de una sociedad global se ha quedado retrasado respecto al de una economía global. A menos que se acabe con esta distancia, el sistema capitalista global no sobrevivirá" (ECA, 1998, p. 900).

No nos vamos a detener a repetir, por todo lo ya visto y escrito, que la economía de libre mercado no es, por sí misma, ni la solución ni el fin de la historia. A sabiendas de que es difícil convertir a los inconvertibles, conviene agregar otros argumentos históricos. "Los efectos de las recientes crisis económicas y financieras han repercutido gravemente sobre muchas personas, reducidas a condiciones de extrema pobreza. Muchas de ellas sólo desde hacía poco tiempo habían alcanzado una situación que justificaba su esperanza alentadora de cara al futuro. Sin ninguna responsabilidad por su parte, tales esperanzas se han visto cruelmente truncadas, con consecuencias trágicas para ellos y para sus hijos" (p. 15). Quizás estas palabras se refieran, en primera persona, a lo tigres o dragones del sudeste asiático y, por carambola, a otros países afectados por el efecto-dominó de esta crisis financiera.

Bajo cualquier hipótesis, e introduciendo una nueva cuña, me vienen al recuerdo expresiones similares de otros autores. Michel Chossudovsky, profesor de la universidad de Ottawa, introduce su artículo sobre la "Guerra financiera" con este párrafo: "La humanidad está sobrellevando en la era de postguerra fría una crisis económica sin precedentes, que conduce al rápido empobrecimiento de grandes sectores de la población mundial. El derrumbe de las monedas nacionales en virtualmente todas las mayores regiones del mundo ha contribuido a la destabilización de las monedas nacionales, mientras precipita a países enteros en una pobreza abismal". Juan Pablo II lo plantea en forma de pregunta: "Y, ¿cómo ignorar los efectos de las fluctuaciones de los mercados financieros? Es urgente una nueva visión del progreso global en la solidaridad, que prevea un desarrollo integral y sostenible de la sociedad, pernitiendo a cada uno de sus miembros llevar a cabo sus potencialidades" (p. 15). Ya es un avance significativo concluir que no vamos bien, sino muy mal, frente a quienes anuncian la bondad del modelo y la esperada llegada del rebalse final.

\subsection{Los mártires blancos del neoliberalismo}

El segundo testimonio, bastante autorizado, sería el discurso ante la Junta de Gobemadores del Banco Mundial, pronunciado el 6 de octubre de 1998, por James D. Wolfensohn, Presidente del Grupo del Banco Mundial. El título es "La otra 
crisis”. En esa semana de octubre 1998 se habían reunido el FMI, Banco Mundial y ministros de finanzas del Grupo G-7 para discutir la crisis financiera mundial, la que a ellos más preocupaba. James Wolfensohn saca, debajo del tapete, la otra crisis mayor y dice palabras que se parecen a las dichas por Juan Pablo II. He aquí una cortas citas:

“Hoy, mis recuerdos son muy distintos. Imágenes sombrías, sobrecogedoras de desesperación, impotencia y miseria. De personas que tuvieron esperanzas, pero las han perdido... Hoy, mientras hablamos de la crisis financiera: 17 millones de indonesios han recaído en la pobreza; y en toda la región, un millón de niños ya no regresarán a la escuela. Hoy, mientras hablamos de la crisis financiera, aproximadamente el 40 por ciento de la población rusa vive en estado de pobreza. Hoy, mientras hablamos de la crisis financiera, en todo el mundo 1,300 millones de personas subsisten con menos de un dólar al dia; 3,000 millones viven con menos de dos dólares al día; 1,300 millones no tienen agua potable; 3,000 millones carecen de servicios de saneamiento, y 2,000 millones no tienen electricidad...

Debemos ir más allá de la estabilización financiera... Porque si no tenemos la capacidad de hacer frente a las emergencias sociales, si no contamos con planes a más largo plazo para establecer instituciones sólidas, si no logramos una mayor equidad y justicia social, no habrá estabilidad política, por muchos recursos que consigamos acumular para programas económicos; no habrá estabilidad financiera... Hemos comprobado que cuando pedimos a los gobiemos que adopten medidas rigurosas para organizar sus economías, podemos generar enormes tensiones. Quien sufre es la gente, no los gobiernos... Debemos tener en cuenta los aspectos financieros, institucionales y sociales. Debemos aprender a entablar un debate en que las matemáticas no valgan más que las razones humanitarias; en que la necesidad de cambios, con frecuencia drásticos, sea compatible con la protección de los intereses de los pobres. Sólo entonces llegaremos a soluciones sostenibles"... (ECA, 1998, pp. 1004...).

Estas pocas frases sueltas pueden significar muchas cosas: parece que hay un reconocimiento y una confesíón implícita de los errores cometidos por esta institución mundial. Parece que hay un propósito de enmienda en la presentación que se hará de nuevos programas de desarrollo en diálogo con los gobiemos. Pareciera que James Wolfensohn se aproximara a M. Gorbachov en su intento de decir una verdad: más economía es más democracia. Lo que sí parece totalmente cierto es que las primeras en no poder controlar la situación mundial son las instituciones financieras intemacionales, inspiradoras del modelo. En anterior artículo recogíamos una pregunta y una respuesta: "A la pregunta: ¿quién está a cargo de la economía global? podemos ahora responder: Nadie. Un mundo sin controles - sin reglas- es un mundo sin seguridad" (ECA, 1998, p. 905). Ese "Nadie" es la especulación financiera, que nadie puede controlar ni tampoco ella puede controlarse a sí misma. Esta es la inseguridad y la insolidaridad de que habla el mensaje papal. 
Ante los efectos de la crisis económica y financiera mundial, Juan Pablo II dirige una exhortación a las grandes autoridades políticas y financieras del mundo. "En este contexto, dirijo una llamada apremiante a los que tienen la responsabilidad a escala mundial de las relaciones económicas, para que se interesen por la solución del problema acuciante de la deuda intemacional de las naciones más pobres. A este respecto, instituciones financieras intermacionales han tomado una iniciativa concreta digna de aprecio. Dirijo mi llamada a todos los que están interesados en este problema, especialmente a las naciones más ricas, para que den el apoyo necesario que asegure el pleno éxito de esta iniciativa. Es preciso un esfuerzo rápido y vigoroso que consienta al mayor número posible de países, de cara al año 2000 , salir de una situación ya insostenible..." (p. 15).

Introducíamos el presente comentario con un ramillete de "impresiones" que nos había creado el presente siglo. Luego de avanzar en la lectura de este mensaje sobre la paz mundial, se agrega una nueva impresión: el siglo XX concluye llevando a cuestas dos grandes problemas -en clave mayor - con que nació hace 100 años: la proletarización creciente y el darwinismo social. Si esto es cierto, ésta es una grave acusación y condena contra los grandes sistemas político-económicos que se han desgastado en sus mutuos enfrentamientos más que en enfrentar los problemas de la humanidad. Como decíamos en anterior publicación, de lo malo sacamos algo bueno: ahora quedamos libres de los dogmas y paradigmas económicos que nos enseñaban e imponían en los respectivos paralelos geográficos. Quedamos libres para la creatividad y el siglo XXI debiera ser el siglo de la creatividad, porque para que las empresas sobrevivan, es menester que la humanidad viva $(E C A, 1998$, p. 908$)$.

\section{Los derechos humanos en el siglo XXI}

Ya no es posible corregir la plana del siglo $\mathrm{XX}$, pero sí es deber nuestro corregir sus errores, si queremos que el siglo XXI tenga tres letras: PAZ. Tal vez, estos mensajes navideños parezcan cartas al Niño-Dios; pero juntando cartas se convierten en una programa de acción. Son un resumen condensado de muchos hechos, y el presente mensaje es el resumen de un siglo que comenzó y que termina mal. No es posible tocar todos sus temas y algunos de ellos necesitan un tratamiento mucho más ampliado, por ejemplo, la creación de la Corte Penal Internacional... Aquí, a modo de conclusión, mencionamos algunos ejemplos, sin mayor comentario.

Hemos recordado el juicio de Nüremberg, en 1945, que nos puede parecer algo lejano y trasnochado. Sin embargo, sigue teniendo gran actualidad en varias regiones del mundo. "La guerra destruye, no edifica; debilita las bases morales de la sociedad y crea ulteriores divisiones y tensiones persistentes... Pero, a su vez, ¿cómo no denunciar las masacres que continúan en otras partes, con la deportación de pueblos enteros de sus tierras y la destrucción de sus casas y cultivos?". 
La frase que sigue es un gravísimo cargo de conciencia para países centrales o megaempresas que, por razones económicas, mueven los hilos de estas guerras. "Ante las víctifnas ya incontrolables, me dirijo a los responsables de las naciones y a los hombres de buena voluntad para que acudan en auxilio de los que están implicados en atroces conflictos, especialmente en África, tal vez inspirados por intereses económicos externos, y les ayuden a poner fin a los mismos. Un paso concreto en este sentido es seguramente la abolición del tráfico de armas hacia los países en guerra... Gérmenes de guerra se difunden también por la proliferación masiva e incontrolada de armas ligeras que, al parecer, circulan libremente de un área de conflicto a otra, sembrando violencia a lo largo de su recorrido" (pp. 1719).

Ojalá que esta exhortación no sea una carta al Niño-Dios, cuando sabemos que los presupuestos militares de las grandes naciones son "top-secret" (Kennet Galbraith) y cuando en el Consejo de Seguridad de Naciones Unidas toman asiento los cinco mayores exportadores de armas. Los estatutos actualizados de Nüremberg debieran incluir entre los crímenes contra la paz el tráfico de armas y, afinando un poco más los estatutos, la avalancha de películas de armas y de violencia, que por cierto circulan de norte a sur. Ojalá que la Corte Penal Internacional lo incluya como punto de agenda. En pocas palabras, continúan los crímenes contra la humanidad, más por razones económicas que ideológicas, porque ahora la rentabilidad es la ideología común.

Juan Pablo II se refiere varias veces a este tema del derecho a la vida, al por mayor. La siguiente cita toca uno de los problemas analizado en el Informe del Desarollo Humano, en 1998 (PNUD): “Optar por la vida comporta el rechazo de toda forma de violencia. La violencia de la pobreza y del hambre, que aflije a tantos seres humanos; la de los conflictos armados; la de la difusión criminal de las drogas y el tráfico de armas; la de los daños insensatos al ambiente natural" (p. 8). "El peligro de daños graves a la tierra y al mar, al clima, a la flora y a la fauna, exige un cambio profundo en el estilo de vida típico de la moderna sociedad de consumo, particularmente en los paises más ricos. No se debe infravalorar otro riesgo, aunque sea menos drástico: empujados por la necesidad, los que viven miseramente en las áreas rurales pueden llegar a explotar por encima de sus límites la poca tierra de que disponen" (p. 16). Este es uno de los puntos que requiere mayor comentario, sobre todo en un país donde el deterioro del medio ambiente equivale al 5 por ciento del producto nacional.

En un año de elecciones y dada la resonancia que ha tenido el documento Bases para un plan de nación, son útiles unas frases sueltas sobre el Derecho a participar: "Cada ciudadano tiene el derecho a participar en la vida de su propia comunidad... No obstante, este derecho se desvanece cuando el proceso democrático pierde eficiencia a causa del favoritismo y los fenómenos de corrupción, los cuales no solamente impiden la legítima participación, sino que obstaculizan el 
acceso mismo a un disfrute equitativo de los bienes y servicios comunes" (p. 10). Este párrafo no nos dice algo extraño para nosotros, pese a las libres elecciones, tal como lo reclaman las encuestas de opinión pública, donde los partidos políticos tampoco salen bien cualificados.

El siguiente párrafo está dirigido simultáneamente al derecho de participación, tanto a nivel intemacional como nacional. "En el ámbito de la comunidad intemacional, las naciones y los pueblos tienen derecho a participar en las decisiones que con frecuencia modifican profundamente su modo de vivir. El carácter técnico de ciertos problemas económicos provoca la tendencia a limitar su discusión a círculos restringidos, con el consiguiente peligro de concentración de poder político y financiero en un número limitado de gobiernos o de grupos de interés. La búsqueda del bien común nacional e intemacional exige poner en práctica, también en el campo económico, el derecho de todos a participar en las decisiones que les conciemen" (p. 11).

Como este párrafo habla del derecho a participar tanto a nivel nacional como intemacional, el Papa estaría poniendo el dedo en uno de los derivados de la globalización neoliberal, analizado y criticado por múltiples autores: la pérdida de la identidad nacional, el debilitamiento de los poderes y políticas estatales e incluso de los valores y tradiciones culturales (ECA, 1998, p. 900...). Ya antes el mensaje nos recordaba los efectos de las fluctuaciones financieras internacionales en las economias nacionales. Esto significa que en el interior de cada nación también se reduce al derecho a la participación en aquellas decisiones económicas que más conciemen a la población. Una de las características de nuestro país, también bajo el actual gobiemo, ha sido la concentración de la toma de decisiones en círculos restringidos del poder político y financiero. Un mérito de los actores de Bases para un plan de nación es que han propiciado las entrevistas y el diálogo con miembros de los departamentos nacionales. Este es un dato que lo debe tener presente el próximo gobiemo si no quiere verse "argollado".

Juan Pablo II nos recuerda que estamos celebrando el " $50^{\circ}$ aniversario de la Declaración Universal de los Derechos Humanos". Por ser universales e indivisibles, el Papa hace una unidad de los derechos civiles y políticos junto con los derechos económicos, sociales y culturales (p. 5-6). Ya hemos escuchado los reclamos de los ciudadanos que en unos países pedían y decían: "no hay pan sin libertad", mientras que del otro lado pedían y decían: "no hay libertad sin pan". Son reclamos que, en una línea, esquematizan las medias tintas y las medias verdades de los grandes sistemas político-económicos.

De acuerdo con la historia, el modelo económico que mejor conjugó estos dos grupos de derechos y que logró simultáneamente mayores tasas de crecimiento, mayor equidad distributiva y mayor (tal vez excesiva) seguridad social, fue el Estado Social de Bienestar. Hoy, en Europa occidental vuelven a sentir nostalgia por la actualización corregida de un modelo que se asentaba en la solidaridad de 
todos los ciudadanos ${ }^{18}$. Decir esto no es un anacronismo; hoy, en esa Europa todos los gobiemos, menos uno, son de centroizquierda. Tal vez ahí renazca en el siglo XXI un modeto inspirador...

Por lo que toca a nuestro continente, el reclamo mayor de las gentes es: "no hay libertad sin pan". Como éste es el reclamo más universal, Juan Pablo II resume este hecho cerrando su mensaje con la parábola del rico-epulón, recordando que epulón significa rico. "Como indica claramente la parábola del rico, que quedará siempre sin nombre, y del pobre llamado Lázaro, es el fuerte contraste entre ricos insensibles y pobres necesitados de todo. Dios está de parte de estos últimos. También nosotros debemos ponemos de esta parte" (p. 21).

La frase final no es un prural maiestático referido sólo a Su Santidad el Papa Juan Pablo II; es un prural real, una exhortación dirigida a todas las jerarquías y jerarcas, y a todos los miembros de la Iglesia. Estas palabras recuerdan lo que Juan Pablo II decía desde África (el continente más pobre) a todas las conferencias episcopales: "la Iglesia debe ser la voz de los que no tienen voz; la Iglesia debe ser como un perro guardián de los derechos sociales". Y exhortaba para que se crearan estas instituciones sociales allí donde no existieran. Esta petición del Papa va más allá de las laudables y necesarias obras e instituciones de beneficiencia y caridad. Se trata de una misión y de una opción preferencial por los pobres, relegados en la creciente proletarización y darwinismo social; se trata de buscar, junto con todos los hombres de buena voluntad, un nuevo orden político y un nuevo modelo económico. El mayor bien común es el bienestar de las mayorías, que el Papa dice son los preferidos de Dios.

\section{Notas}

1. CELAM, "Derechos Humanos", Oficina de Tutela Legal del Arzobispado de San Salvador, 1994.

2. Rodríguez Jiménez, J.L., “¿Nuevos fascismos? Extrema derecha y neofascismos en Europa y Estados Unidos”, Barcelona: Edit. Península, 1998.

3. Courtois E., et al., El libro negro del comunismo: crímenes, terror y represión, Barcelona: Edit. Planeta, 1998.

4. Ibisate, F.J., "Cumbre mundial sobre el desarrollo social, 1995: la pobreza, el desempleo y la desintegración social", Realidad, 42, noviembre-diciembre, 1994.

5. Courtois E., et al., item, p. 18.

6. Ibidem, p. 19-22.

7. Rodríguez Jiménez, J.L., ítem, pp. 32-33.

8. Courtois E., et al., ítem, pp. 28-29.

9. Afasaniev Yuri, Mi Rusia Fatal, Madrid: Edit, Anaya \& Mario Muchnik, 1994, pp. 230...

10. Kaustky Karl, Comunisme et terrorisme, París: Edit. Jacques Povolovky, 1920, p. 164.

11. Courtois E., et al., ítem, p. 829.

12. Ibidem, p. 821. 
13. Ibidem, p. 18.

14. Ibidem, pp. 23-24.

15. Ibidem, Pp. 38-39.

16. Ibisate, F.J., "Sugerencias al neoliberalismo: haga su autocrítica", Realidad, 1998, pp. 9-32; "Neoliberalismo y Globalizacióm", ECA, 1998, pp. 893-907.

17. Whitfield, T., Pagando el precio, San Salvador: UCA Editores, El Salvador, 1998.

18. Ibisate, F.J., "Propuestas de bienestar ¿con Estado de bienestar?", ECA, 1996, pp. 865-887. 